\title{
Survey of ethnobotanical cocktails commonly used in the treatment of malaria in southwestern Nigeria
}

\author{
Rachel Omagha ${ }^{1 *}$ (D), Emmanuel Taiwo Idowu', Chibuisi Gideon Alimba', Adetoro Olubunmi Otubanjo ${ }^{1}$ and \\ Adeniyi Kazeem Adeneye ${ }^{2}$
}

\begin{abstract}
Background: Combination of different antimalarials has become the popular method of care for malaria morbidity in conventional and traditional treatment approaches due to the need to increase the efficacy and reduce the selection of drug resistance. A worrisome concern is the critical gaps with regards to the information available on antimalarial herbal cocktails. This study presents cocktail herbal remedies in ethnomedicinal approaches to malaria treatment in Oyo and Ogun states, South West Nigeria. Ethnobotanical information on indigenous antimalarials used in combination remedies was collected from herbal practitioners using a semi-structured questionnaire.

Results: Findings showed majority of respondents treat malaria with combination herbal remedies. They sighted their beliefs and customs, the efficacy, affordability and availability of these herbs as reasons for their adoption of herbal medicines as their preferred mode of treating malaria. Enquiry revealed 26 sets of cocktail antimalarials from a variety of plant species. The plants and ingredients are extracted and used as decoction, infusion or steam baths. Oral route was the most popular mode of administration. Respondents reported they drink one to two mediumsized cups of the recipe on an average of two times daily within a duration of about 10 days.

Conclusions: Herbal antimalarial remedies continue to be the popular treatments option in our localities. This study provides knowledge of the diverse ways respondents combine medicinal herbs and other local ingredients for malaria treatment. Pharmacological screening is urgently needed to validate their safety and efficacy in order to protect the health of our locals heavily relying on them to combat high burdens of malaria.
\end{abstract}

Keywords: Ethnomedicine, Indigenous antimalarials, Herbal cocktails

\section{Background}

The use of plant materials in the management of illnesses has steadily increased with about $80 \%$ of the world population dependent on the use of herbal medicine in the management of various diseases [1-3]. Malaria is a life-threatening, vector-borne parasitic disease with about 3.2 billion people globally at risk. An estimated 229 million cases of malaria occurred worldwide in 2019, with $94 \%$ of the cases occurring in African

\footnotetext{
* Correspondence: asking4rachel@yahoo.com

'Department of Zoology, Faculty of Science, University of Lagos, Lagos, Nigeria

Full list of author information is available at the end of the article
}

countries [4]. Nigeria suffers the world's largest malaria burden with an estimated value of $45 \%$ prevalence in 2015 among children under 5 years of age [5]. Four species of the protozoan Plasmodium parasite cause malaria in humans. They are Plasmodium falciparum, Plasmodium vivax, Plasmodium ovale and Plasmodium malariae, and these four species have been well reported in Nigeria [6, 7]. However, P. falciparum is responsible for the majority of severe malaria and malaria-associated deaths worldwide, particularly in sub-Saharan Africa [8]. Malaria can be acute, fulminant or chronic. The most frequent clinical manifestation of malaria infection is fever with other symptoms such as headache, nausea, 
vomiting or diarrhea which appear within 7-14 days following the bite of an infected female Anopheles mosquito [9]. When this happens in Nigeria, most people know that it is time to treat malaria either through selfmedication or by visiting medical personnel for treatment [10]. The greatest impact of the disease is on the poor people mostly located in the rural settings with increased poor nutritional status and poor access to good health facilities [11].

The use of malaria preventive measures, such as the long acting insecticide-treated bed nets or insecticidetreated bed nets and indoor residual spraying, have reduced malaria burden and child mortality in Nigeria and other parts of Africa [12, 13]. However, in relative terms, malaria burden has not significantly changed in many highly endemic African countries including Nigeria despite increased coverage of insecticide-treated nets (ITN) [12, 14-17]. Studies in Nigeria showed that though the knowledge of malaria and its preventive measures especially through environment sanitation was high, adherence to use of ITN, indoor insecticide spray and other preventive measures was still below expected targets [15, 18-20]. Effective control has relied upon the success of the antimalarial quinine and artemisinin, both from plant sources [21]. However, there are evidence mounting to suggest that many Plasmodium strains have developed resistance to antimalarial therapies including artemisinin and its derivatives [22]. With this looming threat of artemisinin resistance coupled with limited availability and affordability of pharmaceutical antimalarials especially in poor countries with malaria endemicity, availability of monotherapy agents and lack of adequate information on appropriate use of effective antimalarial drugs [23] continues to create the need to develop new treatments that are better suited to effectively treat malaria. The various providers of health services in Nigeria can broadly be classified into two groups: government-owned health centers and those owned by private organizations and individuals. Additional forms of health providers are the private hospitals that are owned by qualified medical practitioners, licensed pharmacists, the unqualified and unlicensed chemist shop owners, the ubiquitous drug peddlers, traditional drug hawkers and other forms of health providers [24]. The greater number of malaria treatment services are provided through the private retail sector in Nigeria [25, 26]. The increased demand for private health provision which predominantly caters for the middle-class cadre is due to high cost of accessing government specialist hospitals and the bureaucratic structure of general hospitals.

In many developing countries, one-fifth of patients use indigenous herbal remedies to treat malaria [27]. According to the World Health Organization (WHO), herbal medicines are the first line of treatment for $60 \%$ of children with high fever due to malaria in Nigeria, Ghana, Mali and Zambia [28]. Many caregivers resort to the use of various herbal medicines in the management of malaria. A wide variety of plants belonging to several families have been identified through ethnobotanical and ethnopharmacological studies as antimalarial medicinal plants [29] and are in use by majority of the infected populations in malaria endemic countries [30]. In recent time, several of these plants and/or their components are prepared and administered as monotherapy or a mixture of plant formulations by the locals [31-37]. Concoction of two or more plant species has been reported as a common method of herbal remedy preparation in Africa [32, 34, 35]. In Nigeria where the rural dwellers depend more on herbs and other forms of traditional medicines for malaria management, this method of combining two or more plant species that work in synergy [38] is believed to increase the efficacy of herbal remedies and delay the development of malaria parasite resistance [39]. These simple medicinal preparations often mediate beneficial responses due to a variety of their active chemical constituents [40, 41], which are responsible for their medicinal properties [42].

According to UNESCO [43], the usefulness of these medicinal plants may hold the key to another new and effective antimalarial drug in the future. Medicinal plants used in combination as antimalarial remedies are yet to be extensively documented and scientifically reported, despite their increasing popularity as local treatment options. In Nigeria, majority of documented antimalarial plants research has been carried out in the southwest where a lot of the people take advantage of the huge biodiversity of medicinal plants to treat and manage various ailments including the high rate of malaria incidence in the region [31, 44]. This explorative ethnobotanical survey was therefore undertaken in the southwestern regions of Nigeria to identify plants and ingredients traditionally used in some of the numerous antimalarial cocktail treatments and investigate how they are used.

\section{Methods}

\section{Sampling sites description}

A total population of 200 herbal practitioners were interviewed in different communities of two local government areas (LGAs) each in Ogun and Oyo states, South West Nigeria. Ogun state is located in the rainforest zone of southwestern Nigeria where malaria is holoendemic year round. The LGAs Ijebu North and Yewa North are two of twenty LGAs in Ogun state and are located $140 \mathrm{~km}$ northeast and $170 \mathrm{~km}$ north of Lagos in the rainforest zone of southwestern Nigeria. The inhabitants of the two LGAs are predominantly farmers and traders [45]. Oyo state with about 4.5 million people 
predominantly occupied by the Yoruba tribe covers approximately an area of $28,454 \mathrm{~km}^{2}$. The state consists of 33 local government areas including Ibadan South East and Ibarapa Central. The climate is equatorial, notably with dry and wet seasons with relatively high humidity. Agriculture is the main occupation of the people of Oyo state. The state is holoendemic for malaria, which is the commonest reason for hospital outpatient attendance [46].

\section{Sample size determination}

Sample size was determined according to Lemeshow et al.'s [47] table for a minimum sample size using the formula: $n=\mathrm{Z}^{2} \mathrm{P}(1-\mathrm{P})^{2} / \mathrm{D}^{2}$, where $n=$ the sample size, $Z$ $=1.96$ at $95 \%$ confidence interval; $P=$ assumed prevalence of malaria in the states (25\%), and $d=6 \%$ level of significance.

\section{Sampling technique}

A multi-stage sampling technique was adopted in selecting the 200 herbal practitioners that were interviewed. The first step was to randomly select two (Ogun and Oyo) of the six states in southwestern Nigeria using simple random technique. The second step was to select two local government areas from each of the selected states (Ogun [Ijebu North and Yewa North]; Oyo [Ibadan South East and Ibarapa Central]) using simple random technique through balloting. The list of all LGAs in each of the selected states was compiled and placed in two separate boxes. Two LGAs were then randomly picked from each box without replacement. The number of herbal practitioners interviewed is proportional to the population of each LGA. Purposive sampling method was adopted at the third stage of sample selection. Here, communities identified to have high preponderance of herbal practitioners in each of the selected LGAs were purposively selected for the study. Information were collected from males and females age 18 years and above involved in herbal practice and use via face-to-face interviews and aided by trained research assistants. The survey was carried out between October and December 2017 and lasted for five weeks.

\section{Questionnaire design and method of administration}

A semi-structured questionnaire for the survey was prepared with questions bothering on types and parts of plants often used for malaria in combination therapies, methods for preparation and administration. Questions pertaining to socio-demographic characteristics and preferred mode of malaria treatment were multiple choice, while questions about their reasons for herbal use preference, their commonly used plants and ingredients for cocktail antimalarial remedies were open-ended. A pretest of the questionnaire was first carried out in October
2016 under the same conditions expected in the actual fieldwork at Mushin LGA of Lagos state.

\section{Statistical analysis}

The returned questionnaires were cleaned to ensure completeness and thereafter coded using a coding guide. The coded data was subsequently entered into the computer and analyzed using Statistical package for the Social Sciences (SPSS) software version 23.0. In both descriptive and inferential statistics, percentage and frequency were used to analyze data on reported medicinal plant cocktails and associated indigenous knowledge. Data was summarized using tables and charts.

\section{Ethical considerations}

The [Nigerian Institute of Medical Research] reviewed and granted approval (assigned number IRB/17/036) for this study. Each respondent had an informed consent document to read and sign before participating, and their participation was voluntary. Their identities and responses were strictly kept confidential.

\section{Results}

A total number of 111 respondents comprising 67 in Ijebu North and 44 in Yewa North responded to questionnaires in Ogun state. The 89 respondents from Oyo state comprised 64 from Ibadan South East and 25 from Ibarapa Central.

\section{Socio-demographic characteristics of respondents}

The survey showed the proportion of male respondents to be $22.5 \%$, compared to the higher response at $77.5 \%$ observed among the female respondents. Respondents between the ages of 31 and 60 were the highest in this study at 53\%. The proportion of respondents with no education was at $20.5 \%$, while respondents with primary education were $24.0 \%$. Respondents with secondary education were the highest in this study at $30.5 \%$, while those with post-secondary education were at $24.0 \%$. Statistical test showed that there is significant difference in the respondents' level of education $(p=0.013)$. Among the population of respondents, herbal practitioners with $\geq 30$ years of practice were at $46.5 \%$ while those with $20-29$ years practicing experience were $21 \%$. Table 1 shows the socio-demographic characteristics of respondents.

\section{Ways respondents diagnosed malaria}

Results presented in Fig. 1 shows that respondents are aware of the malaria symptoms and identified some of those they base their diagnosis on. The more popular ways they mentioned include headache (Ogun 63.96\% versus Oyo 64.0\%), fever (Ogun 96.4\% versus Oyo 82.0\%), nausea/vomiting (Ogun 73.9\% versus Oyo 68.5\%) 
Table 1 Socio-demographic characteristics of respondents from survey areas

\begin{tabular}{|c|c|c|c|c|c|c|c|c|}
\hline \multirow{2}{*}{$\begin{array}{l}\text { Socio-demographic } \\
\text { characteristics }\end{array}$} & \multicolumn{2}{|c|}{ Ogun state (number $=111)$} & \multicolumn{2}{|c|}{ Oyo state (number $=89$ ) } & \multicolumn{2}{|c|}{ Total $($ number $=200)$} & \multirow{2}{*}{$\begin{array}{l}\text { Chi- } \\
\text { square } \\
\left(x^{2}\right)\end{array}$} & \multirow{2}{*}{$\begin{array}{l}P \\
\text { value }\end{array}$} \\
\hline & Number & $\%$ & Number & $\%$ & Number & $\%$ & & \\
\hline Sex & & & & & & & 3.45 & 0.735 \\
\hline Male & 26 & 23.4 & 19 & 21.3 & 45 & 22.5 & & \\
\hline Female & 85 & 76.6 & 70 & 78.7 & 155 & 77.5 & & \\
\hline Age & & & & & & & 3.34 & 18.830 \\
\hline $18-30$ & 23 & 20.7 & 28 & 31.5 & 51 & 25.5 & & \\
\hline $31-60$ & 61 & 54.9 & 45 & 50.6 & 106 & 53.0 & & \\
\hline $61-90$ & 27 & 24.3 & 16 & 17.9 & 43 & 21.5 & & \\
\hline Religion & & & & & & & 2.01 & 0.374 \\
\hline Christianity & 31 & 27.9 & 32 & 35.9 & 63 & 31.5 & & \\
\hline Islam & 37 & 33.3 & 30 & 33.7 & 67 & 33.5 & & \\
\hline Traditional & 43 & 38.7 & 27 & 62.8 & 70 & 35.0 & & \\
\hline Marital status & & & & & & & 2.53 & 0.631 \\
\hline Single & 19 & 17.1 & 21 & 23.6 & 40 & 20.0 & & \\
\hline Married & 59 & 53.2 & 46 & 51.7 & 105 & 52.5 & & \\
\hline Separated & 15 & 13.5 & 13 & 14.6 & 28 & 14.0 & & \\
\hline Divorced & 7 & 6.3 & 3 & 3.4 & 10 & 5.0 & & \\
\hline Widowed & 11 & 9.9 & 6 & 6.7 & 17 & 8.5 & & \\
\hline Level of education & & & & & & & 14.71 & $0.013^{*}$ \\
\hline No education & 29 & 26.1 & 12 & 13.5 & 41 & 20.5 & & \\
\hline Primary & 30 & 27.0 & 18 & 20.2 & 48 & 24.0 & & \\
\hline Secondary & 27 & 24.3 & 34 & 38.2 & 61 & 30.5 & & \\
\hline Post-Secondary & 23 & 20.7 & 25 & 28.1 & 48 & 24.0 & & \\
\hline Others & 2 & 1.8 & 0 & 0.0 & 2 & 1.0 & & \\
\hline Duration of herbal practice (in years) & & & & & & & 2.86 & 0.963 \\
\hline $0-9$ & 20 & 18.0 & 16 & 17.9 & 36 & 18.0 & & \\
\hline $10-19$ & 17 & 15.3 & 12 & 13.5 & 29 & 14.5 & & \\
\hline $20-29$ & 22 & 19.8 & 20 & 22.5 & 42 & 21.0 & & \\
\hline $30+$ & 52 & 46.8 & 41 & 46.1 & 93 & 46.5 & & \\
\hline Received herbal training & & & & & & & 2.67 & 0.566 \\
\hline Yes & 57 & 56.4 & 46 & 59.7 & 103 & 51.5 & & \\
\hline No & 44 & 43.6 & 31 & 40.3 & 75 & 37.5 & & \\
\hline
\end{tabular}

and body pains (Ogun 96.4\% versus Oyo 82.0\%). Respondents did not diagnose malaria by laboratory techniques.

\section{Mode of treatment of malaria among respondents}

Figure 2 shows that most (58\%) of respondents (Ogun 47.3\% versus Oyo 53\%) mentioned using herbal remedies for malaria treatment. This is in contrast to 13.5\% (Ogun 12.4\% versus Oyo 10.8\%) who adopt orthodox medicines for malaria treatments. Statistical test shows that there is no significant difference in the respondents' mode of treatment of malaria and their LGA of residence.

\section{Reasons for herbal use preference among respondents} Some of the compelling reasons for respondents' preference for herbal use for malaria treatment presented in Table 2 include the following: strong belief in traditional medicine (46\%), belief that herbal medicines are better absorbed, assimilated and excreted by the body (22.5\%), availability around home surroundings (20.0\%) and sheer belief that herbal medicines are better than orthodox medicine (16.5\%). Affordability was also popularly reported as a reason their preferred choice of herbal treatment even though some respondents claimed the cost of preparing these medicines traditionally ranged between 400 and 3000 naira depending on the ingredients required. 


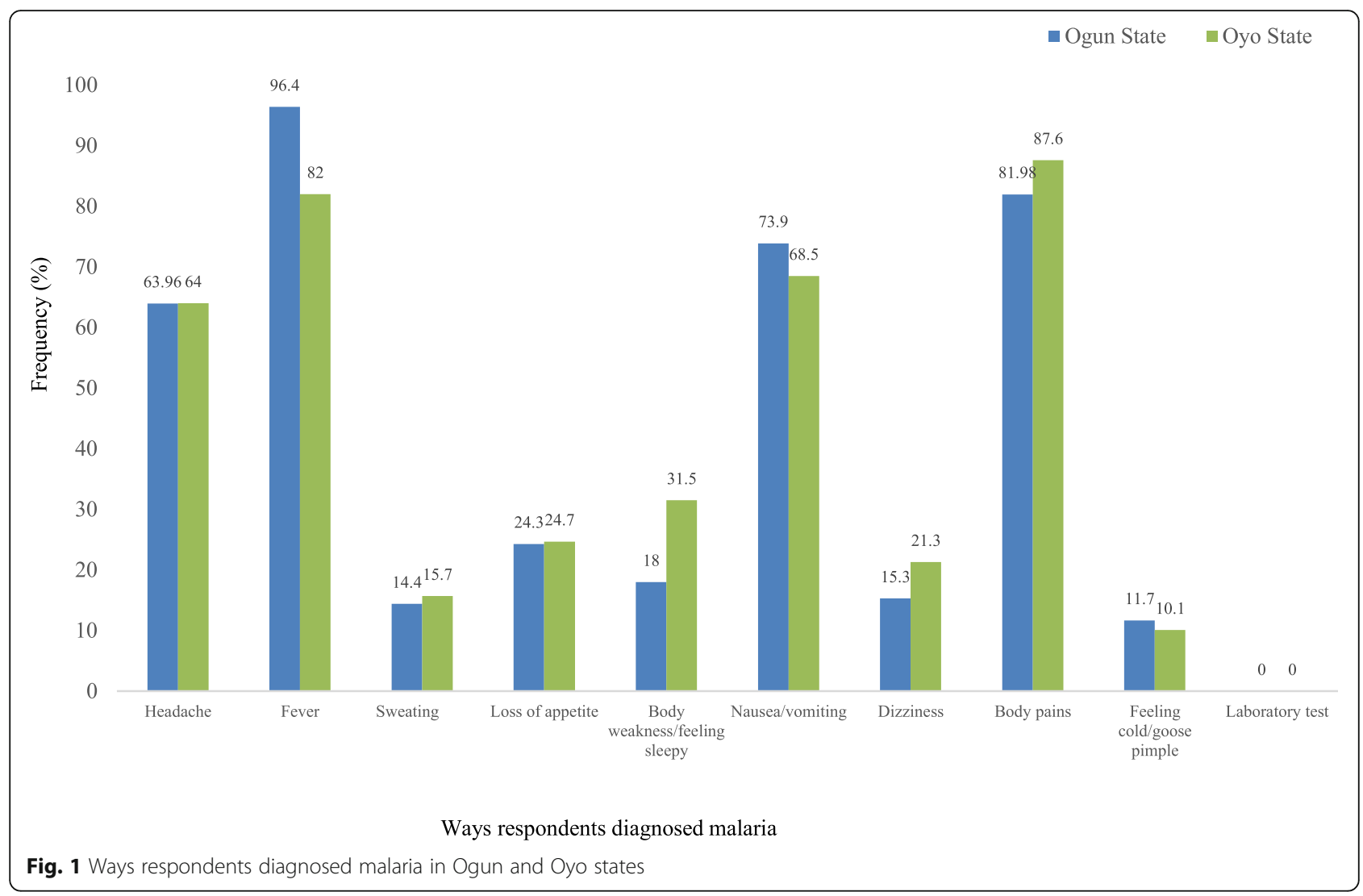

\section{Plants commonly combined for antimalarial cocktail remedies}

Enquiries into traditional folklore revealed 26 sets of cocktail antimalarials from a variety of plant species. Tables 3 and 4 show some of the different antimalarial cocktail preparations from medicinal plants as reported by respondents in areas surveyed. The tables detailed the plants and ingredients combined for each treatment and was compiled according to their generic names, family names, common names, local names, parts of each

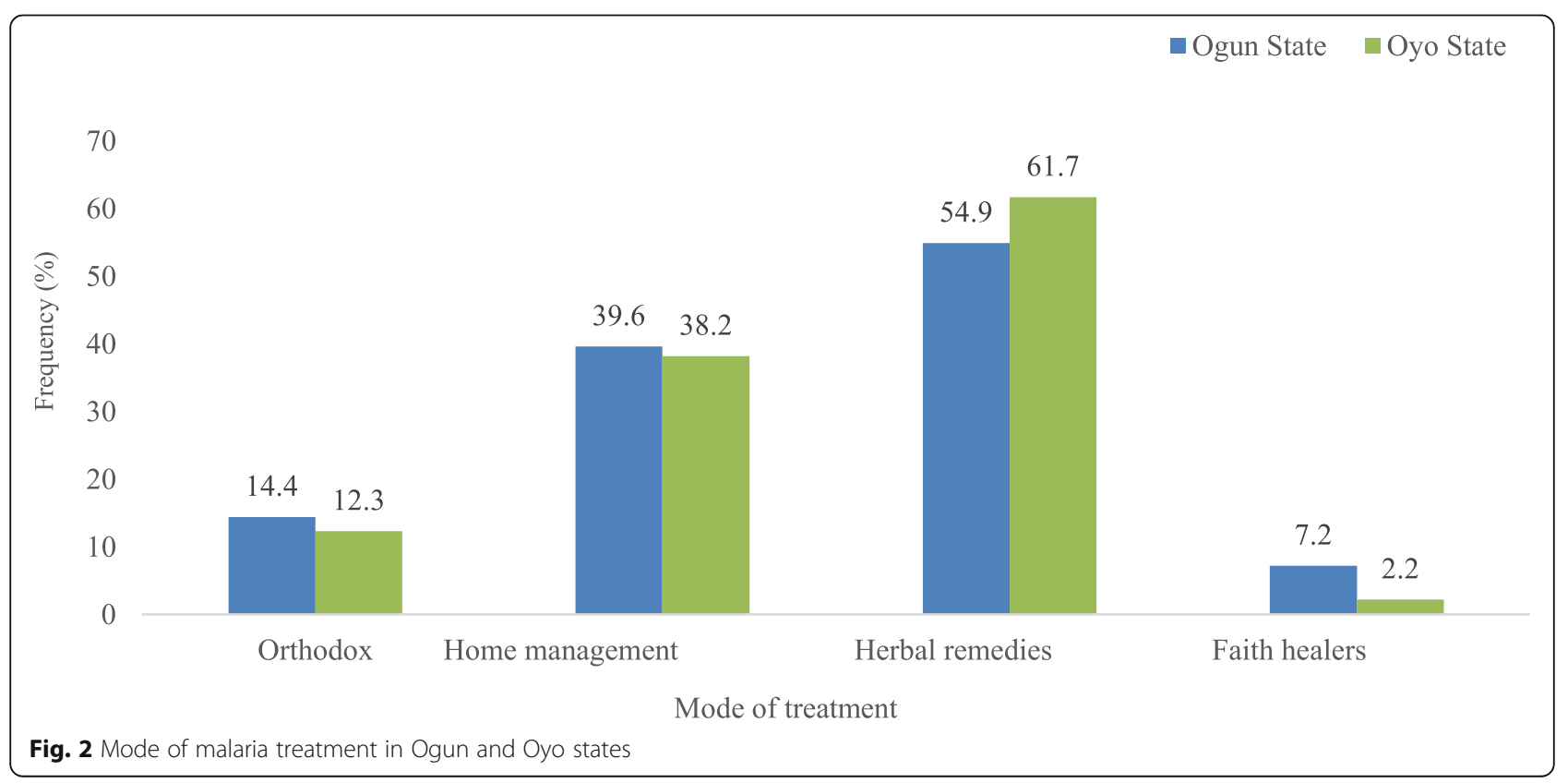


Table 2 Reasons for herbal use preference among respondents

\begin{tabular}{|c|c|c|c|c|c|c|}
\hline \multirow[t]{2}{*}{ Reasons for herbal use preference } & \multicolumn{2}{|c|}{$\begin{array}{l}\text { Ogun state } \\
\text { (number = } \\
111 \text { ) }\end{array}$} & \multicolumn{2}{|c|}{$\begin{array}{l}\text { Oyo state } \\
\text { (number }=89 \text { ) }\end{array}$} & \multicolumn{2}{|c|}{$\begin{array}{l}\text { Total (number } \\
=200 \text { ) }\end{array}$} \\
\hline & Number & $\%$ & Number & $\%$ & Number & $\%$ \\
\hline Affordability & 21 & 18.92 & 18 & 20.22 & 39 & 39.14 \\
\hline Effectiveness/efficacy & 18 & 16.22 & 16 & 17.98 & 34 & 34.2 \\
\hline Faster recovery & 9 & 8.11 & 5 & 5.62 & 14 & 13.73 \\
\hline Natural gift from God, better living & 7 & 6.31 & 3 & 3.37 & 10 & 9.68 \\
\hline Orthodox medicines are harmful & 19 & 17.12 & 14 & 15.73 & 33 & 32.85 \\
\hline Herbal treatments are more reliable than orthodox medicines which are usually fake & 5 & 4.50 & 22 & 24.72 & 27 & 29.22 \\
\hline $\begin{array}{l}\text { Herbal remedies are excreted via urine immediately, while orthodox medicines are stored in the } \\
\text { body }\end{array}$ & 25 & 22.52 & 20 & 22.47 & 45 & 44.99 \\
\hline Herbal mixtures cleanse the body system & 20 & 18.02 & 12 & 13.48 & 32 & 31.50 \\
\hline Availability & 29 & 26.13 & 31 & 34.83 & 60 & 60.96 \\
\hline Stressful waiting in hospital queues & 1 & 0.90 & 0 & 0.00 & 1 & 0.9 \\
\hline Strong belief in traditional medicine & 53 & 47.75 & 39 & 43.82 & 92 & 91.57 \\
\hline
\end{tabular}

plants used, frequency each combination was mentioned, methods of preparing each cocktail treatment and mode of administering these preparations in patients. The cocktail medicines are prepared as water extracts in the form of decoction, infusion or as steam baths. Oral administration through drinking was the only mode of administration of the herbal medicine mentioned by virtually all of the respondents. Respondents reported they take a range of one to two medium-sized cups of the herbal preparation on an average of two times daily within a duration of about 10 days. A few of them however mentioned bathing with or inhaling vapour from the herbal preparation as their mode of administering the antimalarial remedies.

\section{Discussions}

The increasing level of dependence on locally prepared antimalarial therapies makes detailed investigation of them imperative for public safety. Enquiries into traditional folklore antimalarials in Oyo and Ogun states of southwestern Nigeria revealed that a variety of plants, some of which have been scientifically reported to possess antiplasmodial properties, are popularly combined in poly herbal remedies for malaria treatment [31]. A larger number of respondents were observed in the age group 31-60 years which constitutes the most popular working population in Nigeria. The role of exposure and knowledge cannot be over emphasized as it played an influencing factor in the sampled population.

The World Health Organization (WHO) advocates parasitological confirmation with Rapid Diagnostic Tests (RDTs) or microscopy prior to treatment of malaria in all patients [48]. However, respondents in this study did not diagnose malaria by laboratory tests. Rather, they take treatment initiatives based on their recognition of symptoms and signs including fever, headache, nausea, body pains and loss of appetite. Ajibade and Alao [49] previously reported that early signs of fever that prompted mothers to take treatment initiatives were high body temperature and vomiting. The poor malaria diagnostic practice demonstrated through clinical manifestations in this study, and on which treatment is usually based, highlights the need to intensify public health education on the importance of parasitological diagnosis for appropriate case detection, improved patient care and prevention of unnecessary use of herbal remedies.

It is important to emphasize the need for increased public health education on the dangers of selfmedication given that most of the respondents in this study use herbal medicines for malaria treatment, and a few others reported that they treat malaria at home. Respondents had strong belief in the use of herbal medicines and they alluded to their traditions and customs as the driver of their consumption of herbal medicines. Efficacy, availability and the fear of 'fake' orthodox medicines are some other popular reasons reported for their preferred choice of herbal antimalarial treatment. This concern among respondents in the study demonstrate the need for regulatory agencies for herbal medicines to intensify efforts to curb the sale and availability of fake pharmaceutical products particularly herbal antimalarials in the market as a way of increasing the confidence of people in the quality of recommended antimalarial medicines. Another very compelling reason for respondents' preference for herbal use for malaria treatment is cost. Respondents claimed the cost of preparing these medicines traditionally ranged between 400 and 3000 naira depending on the ingredients required. It has been noted 


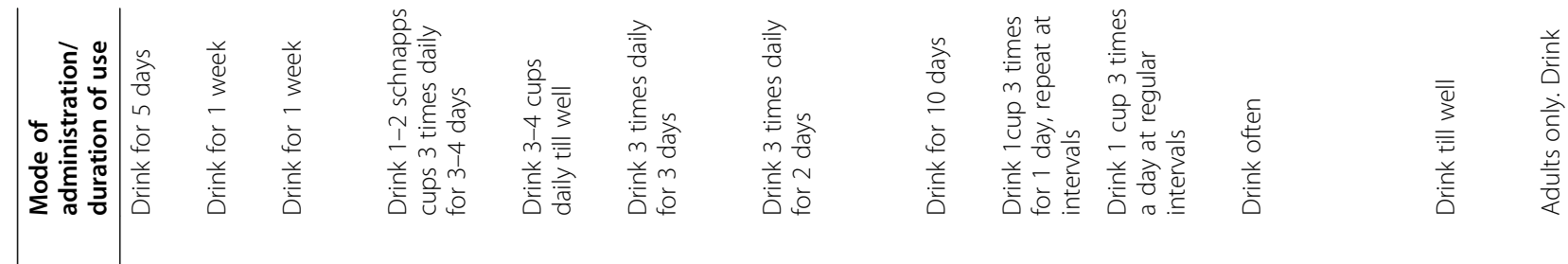

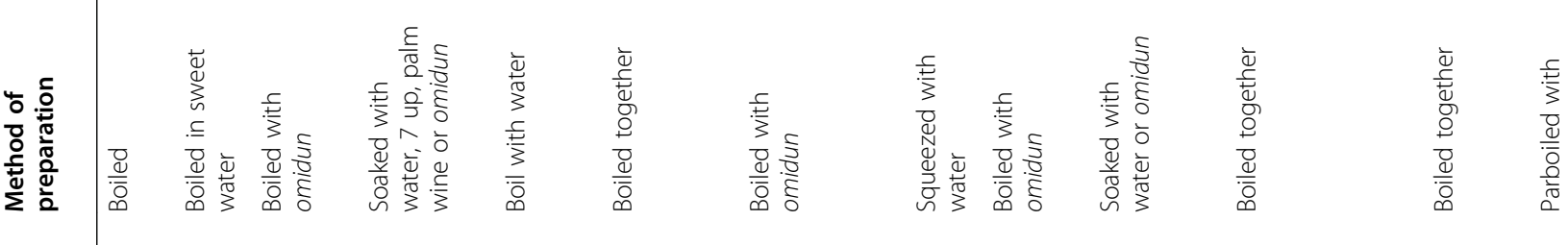

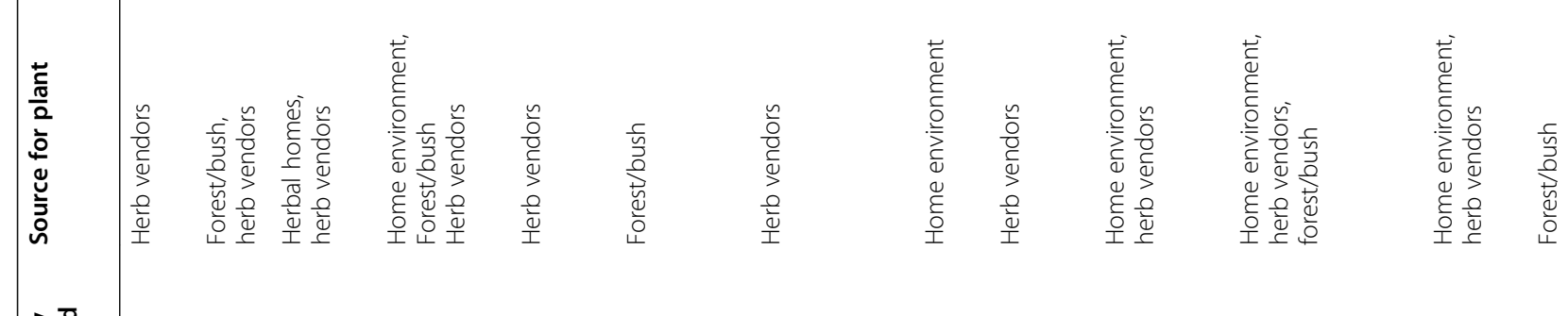

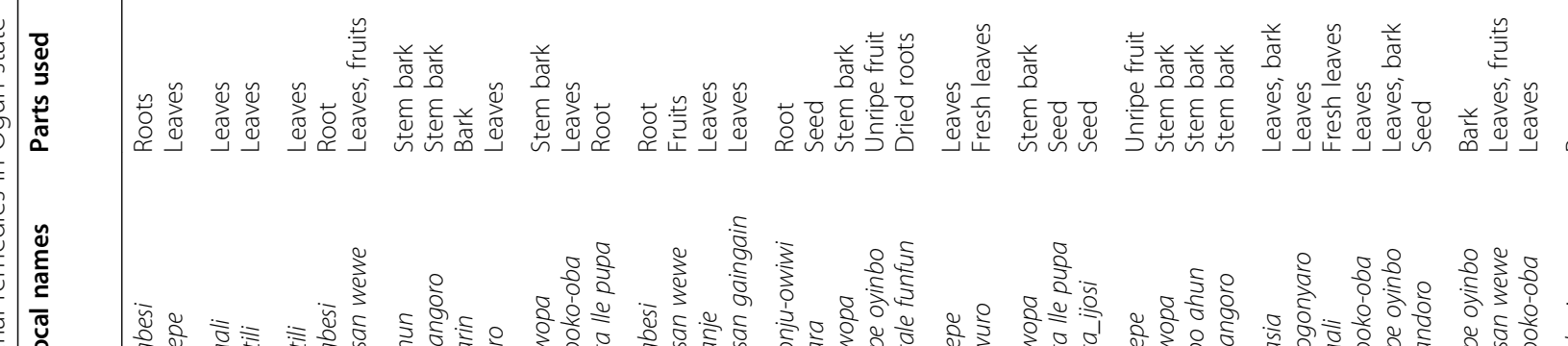

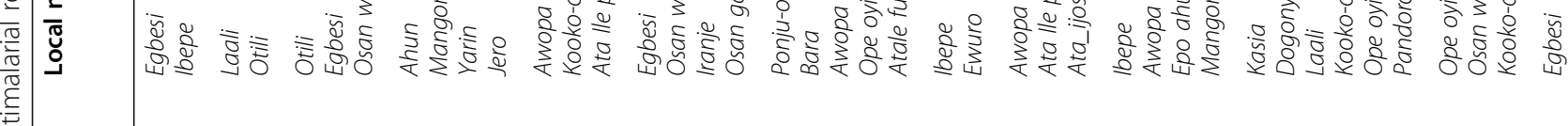

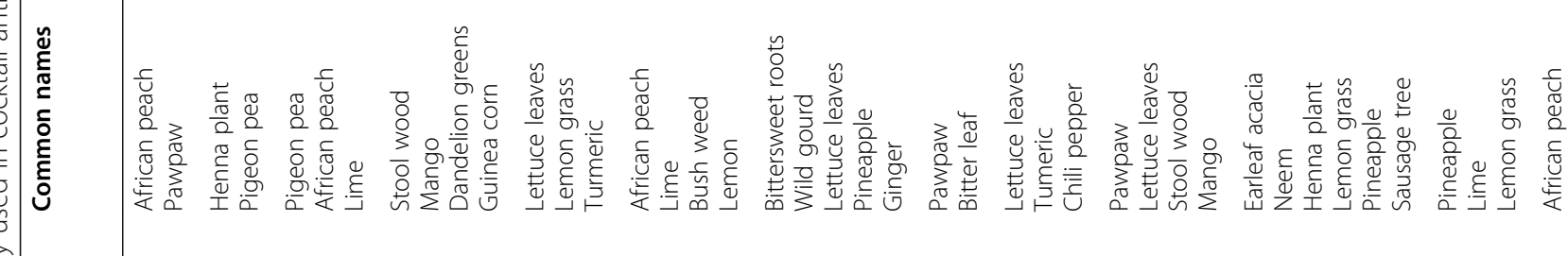

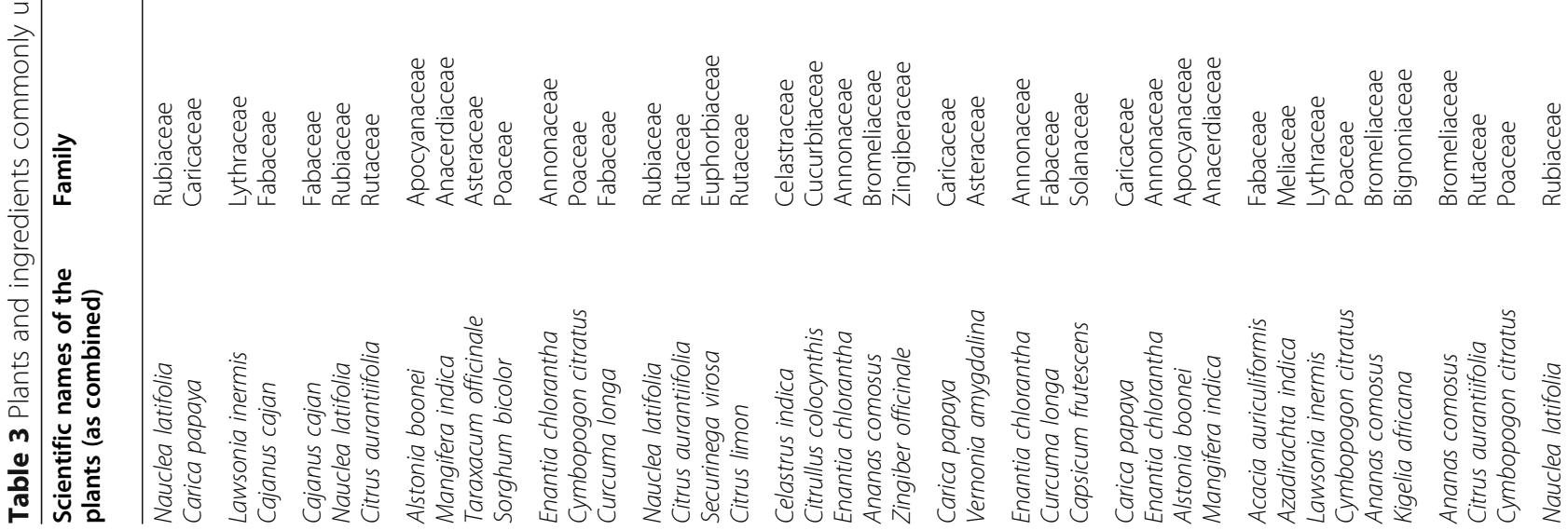




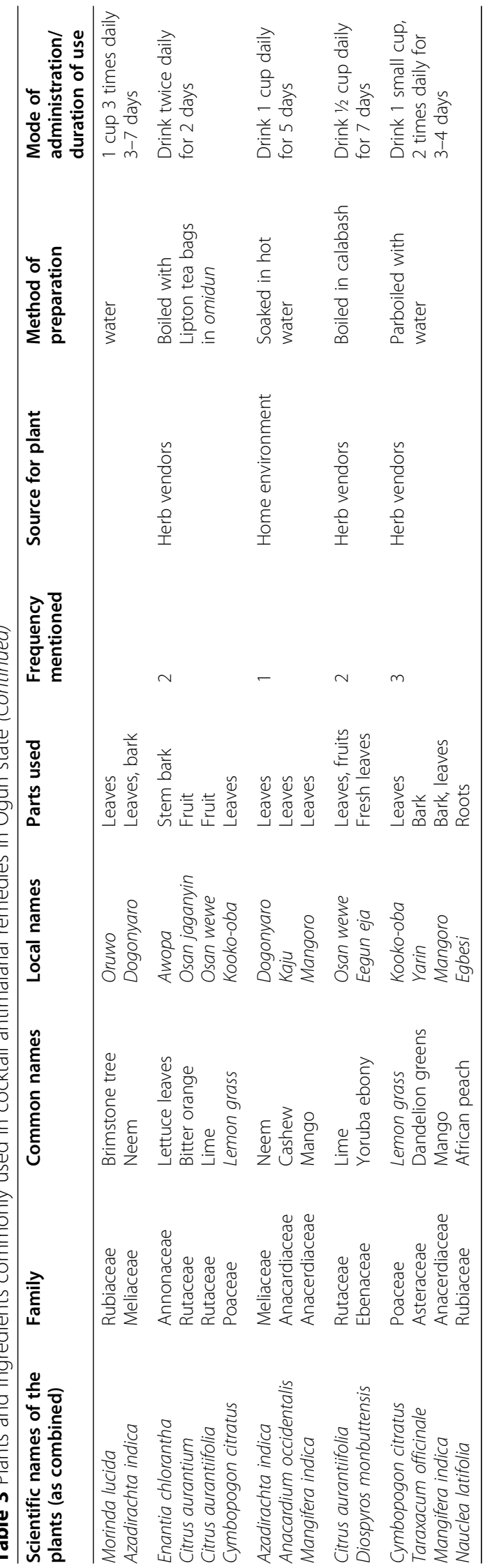




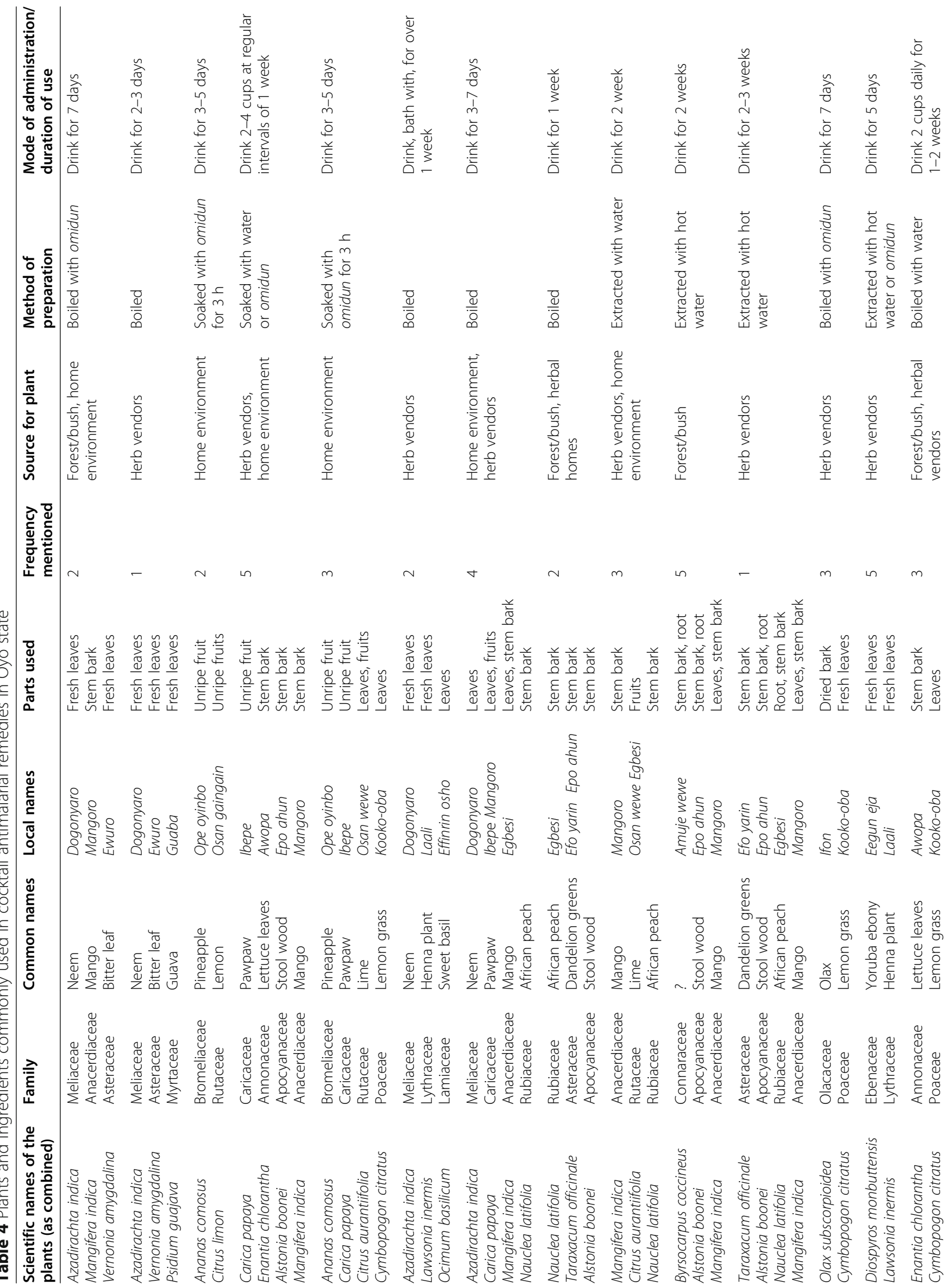




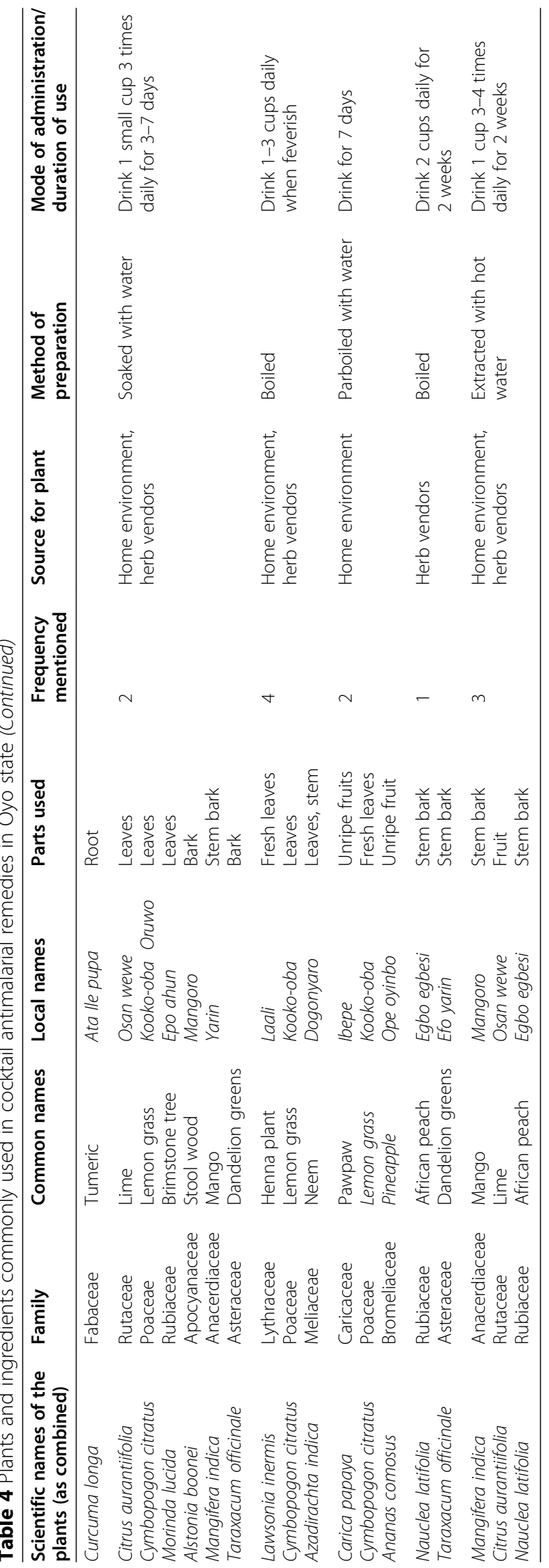


that the availability of genuine conventional antimalarial drugs and the services rendered by private practitioners make the costs generally high and are thus not easily accessible to the poor masses [24]. Since introduction, ACT remains the most expensive antimalarial agent compared to commonly used monotherapy, with a median cost of between 1825 (5 US dollars) and 4015 (11 US dollars) naira per adult dose [50]. Studies on how much Nigerians pay for the less-effective medicines that are widely available and considerably cheaper in privatefor-profit outlets where patients frequently seek malaria treatment [51] need to be explored and compared to the cost of antimalarial treatments with phytotherapies. This will help to identify potential avenues for effective intervention.

Different parts of medicinal plants are now commonly used in combination phytotherapies against malaria [31]. In the present study, a variety of plant parts, mainly fresh leaves are selected and combined in carefully chosen proportions before they are prepared together. These medicines are administered in variable doses and mostly taken at regular intervals over time. Majority of the remedies were administered by oral route, though there were a few mentions of bathing with them or inhaling vapour from them immediately after boiling. Though water is the most popularly mentioned solvent used for the preparations, omidun, a readily available sweet water from fermented corn, alcohol including local gin and palm wine are also used to extract these herbs locally. Notably, respondents failed to indicate how the dosage in the quantity of the herbal remedy was determined. More so, the quantity of the preparation administered and the duration of treatment varied from respondent to respondent. No side effects to these herbal medicines or efforts to standardize their preparation and usage were mentioned or reported. This represents the major drawback of traditional medicine [52].

This treatment strategy employing a variety of herbal preparations is majorly limited by the unavailability of required data on safety and efficacy [53]. A noteworthy observation was that though respondents use these remedies until their recovery, they still continued to administer the herbal remedies at regular intervals. This suggests that most of these remedies as locally used do not provide and maintain the ideal bioavailable level of curative effects, which does not require repeated intermittent administration of treatments. Based on respondents' claims of efficacy and the absence of side effects, the feasibility of discovering new potent antimalarials from these plant formulations vastly used in Nigeria is very promising. To protect the increasing population of people depending on these locally prepared polyherbal antimalarials, actual behaviours of these plant cocktails including their mode of action, potential adverse reactions, contraindications and interactions with existing orthodox pharmaceuticals need to be established by scientific investigation, and findings well communicated to the end users to guide proper and safe use of these remedies. Regulatory and monitoring agencies should ensure effective steps are put in place to protect the health of consumers. Research needs for the development of these phytotherapies that have the potential to treat malaria as effective, safe and readily available antimalarial drugs include precision and standardization of methods of preparation, determining correct dosage and duration of treatments, and critical scientific research to validate efficacy and safety claims.

\section{Conclusion}

Medicinal plant cocktails contribute significantly to current malaria treatment in Nigeria due to its continuous demand to combat malaria. There is no doubt that research on traditional plants will possibly contribute to the discovery of new antimalarial drugs. From these starting points, new treatments can be developed that are better suited to effectively treat malaria. In the meantime, to protect public health, an urgent need remains to understand the divergent preparations and use patterns of antimalarial herbal remedies; to scientifically identify the safest, most effective therapies; to provide countermeasures to associated toxicity risks; and to determine their recommended doses in line with World Health Organization Guidelines and to create awareness for the best options.

\section{Limitations of the study}

Many of respondents were reluctant to part with the information sought. Some of the respondents were willing to exchange information at prices ranging between 20,000 (54.79 US dollars) and 40,000 (109.59 US dollars) naira; some others were adamant for fear of possibly going out of business if they reveal secrets of their trade and deliberately provided limited information on the methods used to prepare the remedies to make it difficult to replicate them. Yet some others insisted they would only reveal such information to their apprentices during training, or to people coming to them through their organization.

\footnotetext{
Abbreviations

WHO: World Health Organization; UNESCO: United Nations Educational, Scientific and Cultural Organization; LGAs: Local Government Areas; SPSS: Statistical Package for the Social Sciences; IRB: Institutional Review Board; p: Probability; RDTs: Rapid Diagnostic Tests
}

\section{Acknowledgements}

The authors are grateful to the herbal medicine practitioners, especially the herb vendors and community members of Ijebu North and Yewa North Local government areas of Ogun state and Ibadan South East and Ibarapa Central local government areas of Oyo state for consenting to participate in 
this study. Our appreciation also goes to the local guards in the communities studied.

\section{Authors' contributions}

IET conceptualized the idea for this study. OR wrote the research proposal. IET, ACG and OAO reviewed the research proposal. OR and AAK conducted the ethnobotanical survey and analyzed the data. OR drafted the manuscript. All the authors participated in reviewing and approving the manuscript for publication. The authors have read and approved the final manuscript.

\section{Funding}

Not applicable.

\section{Availability of data and materials}

The authors have provided data generated and analyzed in the manuscript.

\section{Declarations}

\section{Ethics approval and consent to participate}

The Nigerian Institute of Medical Research Institutional Review Board (NIMR IRB) reviewed and granted approval (assigned number IRB/17/036) for this study. Each respondent had an Informed Consent Document to read and sign before participating, and their participation was voluntary.

\section{Consent for publication}

Not applicable.

\section{Competing interests}

The authors declare that they have no competing interest.

\section{Author details}

'Department of Zoology, Faculty of Science, University of Lagos, Lagos, Nigeria. ${ }^{2}$ Department of Public Health and Epidemiology, Nigerian Institute for Medical Research, Yaba, Lagos, Nigeria.

Received: 31 March 2021 Accepted: 5 July 2021

Published online: 28 July 2021

\section{References}

1. Evans, M. (1994). A guide to herbal remedies. Orient Paperbacks.

2. World Health Organisation (2003). Traditional medicine factsheet.

3. Sharif MDM, Banik GR (2006) Status and utilization of medicinal plants in Rangamati of Bangladesh. Res J Agric Biol Sci 2(6):268-273

4. World Health Organization (2020) World Malaria Report 2020. World Health Organization, Geneva. https://doi.org/10.30875/60123dd4-en

5. Beavogui AH, Delamou A, Camara BS, Camara D, Kourouma K, Camara R, Djimde A (2020) Prevalence of malaria and factors associated with infection in children aged 6 months to 9 years in Guinea: results from a national cross-sectional study. Parasite Epidemiol Control 11:e00162. https://doi.org/1 0.1016/j.parepi.2020.e00162

6. Oboh MA, Badiane AS, Ntadom G, Ndiaye YD, Diongue K, Ndiaye D (2018) Molecular identification of Plasmodium species responsible for malaria reveals Plasmodium vivax isolates in Duffy negative individuals from southwestern Nigeria. Malar J 17(1):1-12

7. Daneshvar C, Davis TM, Cox-Singh J, Rafa'ee MZ, Zakaria SK, Divis PC, Singh B (2009) Clinical and laboratory features of human Plasmodium knowlesi infection. Clin Infect Dis 49(6):852-860. https://doi.org/10.1086/605439

8. World Health Organisation (2020) World malaria report. Switzerland, Geneva

9. Howick VM, Russell AJ, Andrews T, Heaton H, Reid AJ, Natarajan K, Lawniczak MK (2019) The Malaria Cell Atlas: single parasite transcriptomes across the complete Plasmodium life cycle. Science 365(6455):eaaw2619. https://doi.org/10.1126/science.aaw2619

10. Babalola AS, Idowu OA, Sam-Wobo SO, Fabusoro E (2015) Risk factors associated with occurrence of placental malaria in a population of parturients in Abeokuta, Ogun State, Nigeria. Malariaworld J 6(8)

11. Ajala TO, Igwilo Cl, Oreagba IA, Odeku OA (2011) The antiplasmodial effect of the extracts and formulated capsules of Phyllanthus amarus on Plasmodium yoelii infection in mice. Asian Pac J Trop Med 4(4):283-287. https://doi.org/10.1016/S1995-7645(11)60087-4

12. Michael GC, Aliyu I, Grema BA (2017) Knowledge of malaria and adherence to its preventive measures among adults attending out-patient clinics of a
Nigerian tertiary hospital: has anything changed? Afr J Med Health Sci 16(1): 43. https://doi.org/10.4103/ajmhs.ajmhs_81_16

13. Lim SS, Fullman N, Stokes A, Ravishankar N, Masiye F, Murray CJ, Gakidou E (2011) Net benefits: a multicountry analysis of observational data examining associations between insecticide-treated mosquito nets and health outcomes. Plos Med 8(9):e1001091. https://doi.org/10.1371/journal.pmed.1 001091

14. Mukonka VM, Chanda E, Haque U, Kamuliwo M, Mushinge G, Chileshe J, Moss WJ (2014) High burden of malaria following scale-up of control interventions in Nchelenge District, Luapula Province, Zambia. Malar J 13(1): 1-6

15. Akaba GO, Otubu JAM, Agida ET, Onafowokan O (2013) Knowledge and utilization of malaria preventive measures among pregnant women at a tertiary hospital in Nigeria's federal capital territory. Nigerian J Clin Pract 16(2):201-206. https://doi.org/10.4103/1119-3077.110162

16. Landoh ED, Tchamdja P, Saka B, Tint KS, Gitta SN, Wasswa P, De Jager C (2012) Morbidity and mortality due to malaria in Est Mono district, Togo, from 2005 to 2010: a times series analysis. Malar J 11(1):1-7

17. Roca-Feltrer A, Kwizombe CJ, Sanjoaquin MA, Sesay SS, Faragher B, Harrison J, Heyderman RS (2012) Lack of decline in childhood malaria, Malawi, 2001 2010. Emerg Infect Dis 18(2):272-278. https://doi.org/10.3201/eid1802.111 008

18. Singh R, Musa J, Singh S, Ebere UV (2014) Knowledge, attitude and practices on malaria among the rural communities in Aliero, Northern Nigeria. J Fam Med Prim Care 3(1):39-44. https://doi.org/10.4103/2249-4863.130271

19. Efunshile M, Amoo AOJ, Akintunde GB, Ojelekan OD, König W, König B (2011) Use and effects of malaria control measures in pregnancy in Lagos, Nigeria. Korean J Parasitol 49(4):365-371. https://doi.org/10.3347/kjp.2011.4 9.4.365

20. Musa OI, Salaudeen GA, Jimoh RO (2009) Awareness and use of insecticide treated nets among women attending ante-natal clinic in a northern state of Nigeria. Marketing 59(354)

21. Ginsburg H, Deharo E (2011) A call for using natural compounds in the development of new antimalarial treatments-an introduction. Malar J 10(1): $1-7$

22. Ashley EA, Dhorda M, Fairhurst RM, Amaratunga C, Lim P, Suon S, Sopha C (2014) Spread of artemisinin resistance in Plasmodium falciparum malaria. N Engl J Med 371(5):411-423. https://doi.org/10.1056/NEJMoa1314981

23. Dodoo AN, Fogg C, Asiimwe A, Nartey ET, Kodua A, Tenkorang O, OforiAdjei D (2009) Pattern of drug utilization for treatment of uncomplicated malaria in urban Ghana following national treatment policy change to artemisinin-combination therapy. Malar J 8(1):1-8

24. Asakitikpi AE (2019) Healthcare coverage and affordability in Nigeria: an alternative model to equitable healthcare delivery. In: Universal Health Coverage. IntechOpen, London, p 45

25. Goodman C, Patrick Kachur S, Abdulla S, Mwageni E, Nyoni J, Schellenberg JA, Bloland P (2004) Retail supply of malaria-related drugs in rural Tanzania: risks and opportunities. Trop Med Int Health 9(6):655-663. https://doi.org/1 $0.1111 / j .1365-3156.2004 .01245 x$

26. Onwujekwe O, Ojukwu J, Uzochukwu B, Dike N, Ikeme A, Shu E (2005) Where do people from different socio-economic groups receive diagnosis and treatment for presumptive malaria, in south-eastern Nigeria? Ann Trop Med Parasitol 99(5):473-481. https://doi.org/10.1179/136485905X51283

27. Willcox ML, Bodeker G (2004) Traditional herbal medicines for malaria. Bmj 329(7475):1156-1159. https://doi.org/10.1136/bmj.329.7475.1156

28. World Health Organization (2003) The Africa Malaria Report 2003. WHO/ CDS/MAL/2003. 1093. World Health Organization/UNICEF, Geneva

29. Karunamoorthi K, Sabesan S, Jegajeevanram K, Vijayalakshmi J (2013) Role of traditional antimalarial plants in the battle against the global malaria burden. Vector-Borne Zoonotic Dis 13(8):521-544. https://doi.org/10.1089/ vbz.2011.0946

30. Zirihi GN, Mambu L, Guédé-Guina F, Bodo B, Grellier P (2005) In vitro antiplasmodial activity and cytotoxicity of 33 West African plants used for treatment of malaria. J Ethnopharmacol 98(3):281-228. https://doi.org/10.1 016/j.jep.2005.01.004

31. Odugbemi TO, Akinsulire OR, Aibinu IE, Fabeku PO (2007) Medicinal plants useful for malaria therapy in Okeigbo, Ondo State, Southwest Nigeria. Afr J Tradit Complement Alternative Med 4(2):191-198

32. Adekunle MF (2008) Indigenous uses of plant leaves to treat malaria fever at Omo Forest reserve (OFR) Ogun state, Nigeria. Ethiopian J Environ Stud Manage 1(1):31-35 
33. Adebayo JO, Krettli AU (2011) Potential antimalarials from Nigerian plants: a review. J Ethnopharmacol 133(2):289-302. https://doi.org/10.1016/j.jep.201 0.11 .024

34. Musa MS, Abdelrasool FE, Elsheikh EA, Ahmed LA, Mahmoud ALE, Yagi SM (2011) Ethnobotanical study of medicinal plants in the Blue Nile State, South-eastern Sudan. J Med Plants Res 5(17):4287-4297

35. Maroyi A (2013) Traditional use of medicinal plants in south-central Zimbabwe: review and perspectives. J Ethnobiol Ethnomed 9(1):31. https:// doi.org/10.1186/1746-4269-9-31

36. Conrad OA, Uche Al (2013) Assessment of In vivo antioxidant properties of Dacryodes edulis and Ficus exasperata as anti-malaria plants. Asian Pac Trop Dis 3(4):294-300. https://doi.org/10.1016/S2222-1808(13)60072-9

37. Ajayi EIO, Adeleke MA, Adewumi TY, Adeyemi AA (2017) Antiplasmodial activities of ethanol extracts of Euphorbia hirta whole plant and Vernonia amygdalina leaves in Plasmodium berghei-infected mice. J Taibah Univ Sci 11(6):831-835. https://doi.org/10.1016/j.jtusci.2017.01.008

38. Adjanohoun JE, Aboubakar N, Dramane K et al (1996) Contribution to ethnobotanical and floristic studies in Cameroon. Scientific, Technical and Research Commission, Organization of African Unity, Addis Ababa

39. Sendagire H, Kaddumukasa M, Ndagire D, Aguttu C, Nassejje M, Pettersson M, Kironde F (2005) Rapid increase in resistance of Plasmodium falciparum to chloroquine-Fansidar in Uganda and the potential of amodiaquineFansidar as a better alternative. Acta Tropica 95(3):172-182. https://doi.org/1 0.1016/j.actatropica.2005.06.003

40. Omagha R, Idowu ET, Alimba CG, Otubanjo AO, Agbaje EO, Ajaegbu HCN (2020) Physicochemical and phytochemical screening of six plants commonly used in the treatment of malaria in Nigeria. J Phytomed Ther 19(2):520-538

41. Park EJ, Pezzuto JM (2002) Botanicals in cancer chemoprevention. Cancer Metastasis Rev 21(3-4):231-255. https://doi.org/10.1023/A:1021254725842

42. Nkunya HMH (1996) Unusual metabolites from Tanzanian Annonaceous plants: the genus Uvari. Int Organ Chem Sci Dev 41. University of Zimbabwe Publications, Harare

43. UNESCO (1998) Promotion of ethno botany and the sustainable use of plant resources in Africa. Terminal Report. UNESCO, Paris, p 60

44. Olorunnisola OS, Adetutu A, Balogun EA, Afolayan AJ (2013) Ethnobotanical survey of medicinal plants used in the treatment of malarial in Ogbomoso, Southwest Nigeria. J Ethnopharmacol 150(1):71-78. https://doi.org/10.1016/j. jep.2013.07.038

45. Adeneye AK, Jegede AS, Nwokocha EE, Mafe MA (2014) Perception and affordability of long-lasting insecticide-treated nets among pregnant women and mothers of children under five years in Ogun State, Nigeria. J Infect Public Health 7(6):522-533. https://doi.org/10.1016/j.jiph.2014.07.008

46. Olugbade OT, Ladipo TO, Isreal O, Adedire EO, Adedokun B, Ajumobi O, Ajayi I (2014) Malaria surveillance system evaluation, Oyo state, Nigeria 2012. Int J Infect Dis 21:275-276. https://doi.org/10.1016/j.jiji.2014.03.992

47. Lemeshow S, Hosmer DW, Klar J, Lwanga SK, World Health Organization (1990) Adequacy of sample size in health studies. Wiley, Chichester

48. World Health Organization (2010) Guidelines for the treatment of malaria -2nd edition. World Health Organization/UNICEF, Geneva

49. Ajibade BL, Alao MT (2013) Mothers' action and preferences of treatment of febrile illnesses among under-five-year-old children in Osun State. J Biol Agric Healthc 3(7):148-155

50. Ezenduka CC, Okonta J, Ogbonna BO (2013) Survey of antimalarial drugs prices and availability in retail outlets in Enugu urban South East Nigeria. Value Health 16(3):A96. https://doi.org/10.1016/j.jval.2013.03.451

51. Rao VB, Schellenberg D, Ghani AC (2013) Overcoming health systems barriers to successful malaria treatment. Trends Parasitol 29(4):164-180 https://doi.org/10.1016/.jpt.2013.01.005

52. Asase A, Oteng-Yeboah AA, Odamtten GT, Simmonds MS (2005) Ethnobotanical study of some Ghanaian anti-malarial plants. J Ethnopharmacol 99(2):273-279. https://doi.org/10.1016/j.jep.2005.02.020

53. Rasoanaivo P, Wright CW, Willcox ML, Gilbert B (2011) Whole plant extracts versus single compounds for the treatment of malaria: synergy and positive interactions. Malar J 10(1):1-12

\section{Publisher's Note}

Springer Nature remains neutral with regard to jurisdictional claims in published maps and institutional affiliations.

\section{Submit your manuscript to a SpringerOpen ${ }^{\circ}$ journal and benefit from:}

- Convenient online submission

- Rigorous peer review

- Open access: articles freely available online

- High visibility within the field

- Retaining the copyright to your article

Submit your next manuscript at $\boldsymbol{\nabla}$ springeropen.com 